University of Northern Colorado

Scholarship \& Creative Works @ Digital UNC

$1-1-2004$

Paper Trail: One Method of Information Literacy Assessment

Jennifer Nutefall

Follow this and additional works at: https://digscholarship.unco.edu/libfacpub

Part of the Library and Information Science Commons 


\title{
Paper Trail: One Method of Information Literacy Assessment
}

\author{
Nutefall, Jennifer E. \\ Melvin Gelman Library, George Washington University \\ jennifer.nutefall@oregonstate.edu
}

This is the author's peer-reviewed final manuscript, as accepted by the publisher. The published article is copyrighted by Elsevier and can be found at:

http://www.elsevier.com/wps/find/journaldescription.cws home/620212/description\#description

Citation: Nutefall, J. E. (2004). Research Journal: One method of information literacy assessment [Electronic version]. Research Strategies, 20(1-2), 89-98. doi:10.1016/j.resstr.2005.07.004 


\title{
Paper Trail: One method of information literacy assessment Jennifer Nutefall
}

\author{
Melvin Gelman Library, George Washington University, 2130 H Street NW, Washington, \\ DC 20052, USA
}

\begin{abstract}
:
Assessing students' information literacy skills can be difficult depending on the involvement of the librarian in a course. To overcome this, librarians created an assignment called the Paper Trail, where students wrote a short essay about their research process and reflected on what they would do differently. Through reviewing and grading these papers, librarians determined whether students understood the difference between the library catalog and article databases, evaluated the students' search terms to see if they used effective topic keywords and Boolean operators, and learned more on how the students reflected on their research process.
\end{abstract}

Corresponding author. Tel.: +1-202-994-9863.

E-mail address: jnutefal@gwu.edu

The author was formerly Reference/Instruction Librarian at State University of New York, College at Brockport. 


\section{Background}

Recognizing the importance of teaching students to be information literate, the SUNY Board of Trustees, the governing body of the State University of New York system, included information literacy in a series of general education mandates it issued in 1999 for each campus to meet (Trustees' Resolution 98-241: General Education Requirement). The Trustees mandated that students be able to "demonstrate understanding of and use basic research techniques," "locate, evaluate, and synthesize information from a variety of sources," and "identify, analyze, and evaluate arguments as they occur in their own and others' work." These mandates parallel the commonly used definitions of information literacy. Also among the Trustees mandates were provisions that students "show proficiency in public speaking in a variety of contexts" and "evaluate public speaking according to established criteria."

After the Trustees issued their mandates, it was up to each of the 64 SUNY campuses to decide how to meet them. At SUNY Brockport, the decision was made to revise the general education curriculum. In its early stages, a one-credit information literacy class

and a two-credit public speaking class were proposed. Academic departments, including the library, submitted comments in response to the proposed changes. The library's response stated in part:

Librarians working in concert with the faculty will challenge the librarians to know the curriculum and the faculty working in concert with librarians will challenge the faculty to know library resources, both of which can only benefit 
student success....The opportunity that exists now is to include the librarians to assist in the definition and clarification of specific criteria within trusteesmandated student learning outcomes that address information literacy so that we can assess whether or not our students are learning information processing and research skills.

After numerous changes over the course of a full year, the curriculum was finalized to include a new three-credit general education course entitled "Oral Communication and Information Literacy," or CMC 111. Based on the library's response to the proposed changes and in consultation with the Communication Department, the decision was made to have the course co-taught by the Communication Department and the library.

During the summer of 2000, the Communication Department hired a new faculty member to serve as coordinator for CMC 111 and the library appointed a Reference/Instruction Librarian to act as the library's liaison. Through discussion, its was decided that the library would have three weeks during the semester to teach information literacy skills. To better integrate those skills, the weeks would be interspersed during the course of the semester, to coincide with specific assignments. This would give the librarian the opportunity to be present in class at different points during the course of the semester, making the librarian more visible and familiar to the students. 


\section{Literature Review}

According to Angelo, "Assessment is an ongoing process aimed at understanding and improving student learning" (p. 7). With the increasing emphasis on assessment from accreditation agencies and state governing bodies, it is important for libraries and librarians to become involved in assessment.

There are two main types of assessment: quantitative and qualitative. A good distinction is made in Qualitative Inquiry: A Dictionary of Terms, where it states, "Perhaps the clearest use of the adjective is to distinguish between qualitative data - nonnumeric data in the form of words - and quantitative data - numeric data" (p. 130). In social science research, the common methods used for collecting qualitative data include unstructured open-ended interviews and participant observation, while quantitative data collection methods include questionnaires and tests.

Applying quantitative and qualitative assessments to information literacy and library instruction can be difficult because of the types of instruction librarians provide. In the library literature, there are very few articles that discuss integrating both quantitative and qualitative assessment methods in a variety of library instruction settings. Rabine (2001) discusses several types of assessment on both a program and individual class level, including surveys, post-tests, open-ended questions, questionnaires, and a self-assessment from the librarian. In a discussion on assessment used for freshmen students, Knight (2002) includes a multiple-choice online exercise, pre- and post-tests and a worksheet. 
D'Angelo (2001) shows the evolution of an assessment instrument in a gateway course, which includes pre-tests, handouts, one-minute papers and inclusion in the assignment itself. Along with the methods mentioned above, Carter (2002) describes informal students focus groups as a way to gather assessment information. She also describes a free response test given to freshman to measure both the attitude of students toward the library and the usage of library resources. Another interesting article by Maughan (2001) elaborates on the experience at the University at California-Berkeley of surveying graduating seniors in selected departments on their information literacy skills.

Williams (2000) presents a number of examples of assessment ideas and includes information on the skills and knowledge assessed and the strengths and potential weaknesses of different assessment methods. Williams also states that, "no single form of assessment is correct for all situations, and many forms will work in similar situations" (p. 332).

All of the articles mentioned discuss a mix of both quantitative and qualitative methods. In planning CMC 111, this was taken into consideration. Quantitative assessment methods included the mid-term and final exam, which are multiple choice. Qualitative assessment methods included the information literacy assignments, most specifically the Paper Trail assignment. To better understand how the Paper Trail assignment works as an effective assessment method, an understanding must be gained of the course. 


\section{Course Design}

When it came time to develop the curriculum of CMC 111, the library wanted to create a uniform curriculum so all students would be getting the same information literacy skills that could be built upon in later years. First, the decision was made to find a textbook that covered the information the library planned to teach. The librarians believed it was important to have a textbook for the information literacy portion of the class, both because it would reinforce concepts and because it would give the curriculum credibility in the eyes of the students. After identifying four possibilities and looking individually at each one, librarians, along with the faculty member from the Communication Department, chose Carla List's Introduction to Information Research (1998), because of its coverage and readability.

Each week of the library's curriculum had a particular focus to blend better with the public speaking curriculum. The focus of the first week was information characteristics, controlled vocabulary, database construction, using the library catalog, citation styles and plagiarism. During the second week, students' were taught how to find articles using Boolean operators and advanced searching techniques, and how to search and evaluate information found on the web. In the third week, students' were exposed to using print reference materials and the social, legal and ethical issues of information literacy, such as copyright and privacy. Although the curriculum was developed with input from the librarians, the library liaison for CMC 111 created a curriculum guide for each day that lists the chapters or pages being covered, material to bring to class, related assignments or 
exercises, a detailed outline of what should be covered, and approximately how long each topic should take.

As the course was being developed, assessment was always a consideration. It was decided that the information literacy assessment for CMC 111 would have two components: The score of the mid-term and final exam and the Paper Trail Assignment. For the mid-term and final exam, the library had anywhere between 15-20 multiple choice questions that covered information literacy skills. These questions drew on material taught in class and from the textbook. The second assessment method was the information literacy assignments and specifically the Paper Trail, which required students to both perform various tasks and reflect on their experiences.

\section{Assignments}

There were six information literacy assignments, which were graded to give them more weight and importance with the students. Out of a total of 1000 points for the whole course, the assignments were worth 25 points each, while the Paper Trail was worth 50. This paralleled the other assignments the students completed for the public speaking portion of the course.

Here are brief descriptions of each of the six information literacy assignments:

1. The Organization of Information (adapted from Faust, Ginno, Laherty and Manuel) 
This assignment will have the students fill out a chart that will ask them to take a group of objects they have organized or plan to organize and describe four different methods of organizing the objects. The students will then describe the advantages and disadvantages of each method of organization. This assignment will allow students to see how complex the task of organizing information is and give them a better understanding of the principles behind library organization.

\section{Searching the Library Catalog}

This assignment has the student practice searching the library catalog to see the difference between keyword and subject searching. It also takes them through the different search features available when looking for books and journals.

\section{Online Periodical Databases}

Students work in groups to see how concepts discussed in class work with a practical example. The worksheet asks students to describe the content of a database as well as its searching capabilities and come up with specific searches to show the rest of the class. With groups searching different databases, the knowledge is pooled at the end as the worksheets are distributed to the rest of the class.

\section{Web Evaluation}

This assignment requires that the students look at an individual web site (either their choice or assigned), and evaluate it using criteria discussed in class. Evaluation criteria include accuracy, authority, objectivity, currency and coverage. 


\section{Searching the Reference Collection}

The purpose of this assignment is to have students explore the various print resources held within the reference collection and to discover the differences between general and subject specific reference tools.

\section{The Paper Trail}

The original idea for the Paper Trail assignment came from the curriculum sent by University of Rhode Island Librarian Mary MacDonald. On the syllabus for LIB 120: Introduction to Information Literacy, the assignment read:

Essentially the Paper Trail is an annotated portofolio of the research process used for a research paper or project. Your Paper Trail project should allow me to follow it as a map to trace all of your research-the processes that worked and those that didn't work.

From this description, the Paper Trail sounded like an excellent assessment method for

CMC 111. Although changed slightly, the essense of the assignment is the same. Below is the description of the Paper Trail used in CMC 111.

\section{The Paper Trail}

In conjunction with the completion of each student's informative speech, they will argue for the merit of the research process that led them to create their speeches in this two-to-four page essay. The Paper Trail should allow the librarian and the communication professor to trace all of a student's research. 
The Paper Trail assignment also required that students reflect on their research process, describing what worked, what did not, and what they would change. Since the assignment was graded by both the librarian and the communication professor, it was necessary to make explicit the criteria for what the paper should include (see Appendix). It was also decided that the communication professor would grade the writing of the paper and citation style for the five required sources, while the librarian would grade the process the students went through and their reflection on that process. These criteria tie back to the learning objectives for the course: students will "demonstrate understanding of and use basic research techniques," "locate, evaluate and synthesize information from a variety of sources," and "identify, analyze, and evaluate arguments occurring in their own and others' work."

The Paper Trail was initially planned as an end-of-semester assignment. However, because of the addition of a research paper in conjunction with the students' final persuasive speech, the Paper Trail moved to the $10^{\text {th }}$ week of the semester. This was more effective because it left time for the librarians and communication professors to review the students' progress and make suggestions before the final speech and the research paper based on that speech were due at the end of the semester.

In terms of assessment, the Paper Trail is an excellent example of how the students put to use the skills they learned in the course. Librarians determined whether students understood the difference between the library catalog and article databases and looked at 
their search terms to see if they used effective topic keywords, combined keywords with Boolean operators and used varying terms to search for their topic. Librarians also gained insight into how long students spent searching for information in terms of library resources and the web.

\section{Grading Criteria}

When grading the Paper Trail assignment, librarians had six specific criteria for grading as well as a grade based on the students' reflection on the research process (see Appendix). Each student first had to identify a need for information. Essentially the librarians wanted to know how the student chose the topic for their speech. Students chose their topics based on a variety of factors, including personal experience, previous work experience, and future career. One student wrote, “I'm doing my informative speech on binge drinking because it's something that college students can easily relate to. It goes on all the time in high school and college and I also knew a kid who died from binge drinking at M.I.T. so it's an issues I've always paid attention to.”

Having the student determine whether they needed background information was the second criteria in grading. Since most students choose topics of interest to them, they briefly explained what they already knew about the topic before starting their research process. One student, researching the positive and negative factors of marijuana, wrote, "I already knew that most people already knew what marijuana does, what a leaf looks like, and that it is a narcotic. I was pretty sure that I knew some benefits such as for cancer and chemotherapy, but I needed to find more little known facts." 
The third grading criteria had the students determining what types of information they needed. This provided insight into where the students were looking for information and whether they tried strategies that were not covered in class. A student doing a speech on body piercing wrote, "Finally, I used Lexis/Nexis to see if there are any court cases about body piercing, and lo and behold, the search turned up the case of Hines v. Caston School Corporation, which related perfectly to my topic."

Many of the papers showed that students still had difficulty understanding the difference between the library catalog and article databases. One student wrote, "The first thing I did was to search the Brockport Library catalogue for magazine articles and abstracts." Another wrote, "I remembered that during one of the classes in the library, we did an activity on different search engines on the Internet. My group had to research ProQuest." The student went to write how she did her search, came up with more than 10,000 articles and tried to narrow her search.

A fourth factor in grading was seeing if students used a variety of locations where resources could be found. Since the majority of students were doing speeches on popular culture topics, they were able to find the books and articles they needed in the library and did not have to use interlibrary loan. However, some students noted that the books they were using were older then they would have preferred. If they had searched other library catalogs or a database such as WorldCat, they may have been exposed to more recent publications that they could have requested through interlibrary loan. 
The students' use of Boolean operators was also a factor in grading. Depending on the topic, the use of Boolean operators was not always necessary, but a majority of students experimented with combining their search terms. One student, researching individuals with development disabilities, wrote how she first searched terms individually and was not pleased with the results. She used terms such as inclusion, disabilities and developmental disabilities. She continued, "I then decided to use a Boolean operator. I was very happy with what this led me to."

One of the key elements in grading the papers was how clearly the students explained their thought processes while conducing their research and how they determined what information to use for their speech. Students were very specific in outlining where they started searching for information, how successful they were and where they went to continue their search. One student wrote, "When choosing information, I searched for the most interesting and little-known facts. I felt that by finding the more shocking negative health effects my speech would be more interesting to my audience."

Students were also graded on their reflection of the research process. Factors addressed in this section included anything the student might have done differently and a brief reflection on what they learned from the experience. In the reflection part of the paper, one student wrote: "Using different search methods greatly helped the structure of my speech. The use of the Internet as well as texts gave my speech a more well-rounded and unbiased view. I am glad that I was aware of how to use the searches, for example 
phrasing my topic in many different ways helped me obtain greater search results." Another student wrote that research could be frustrating at times but by using different keywords or trying Boolean operators, they had success in finding the information they needed.

\section{Evaluation}

Librarians believe the Paper Trail, in conjunction with the mid-term and final exams, offer a more complete picture in terms of assessment then just the exams alone. Having students write about their research process allowed the librarian to gain insight into students' behavior and see if the learning objectives for the course were being met. One of the other interesting aspects of the assignment was the reflection and evaluation. Many students reflected on how they wished they had started earlier.

At the end of the fall 2001 semester, librarians discussed and compared students' Paper Trail papers to find common elements, to look at how the students met the grading criteria, and to see what areas within the curriculum students were having problems learning. Each librarian shared their thoughts on the commonalities they saw in the papers they graded. What librarians discovered was that the vast majority of students started their research by going to a general search engine. Although this was not surprising, it was interesting to see students explain how much time they spent on this, how they searched (including using Boolean operators), what information they found and where they decided to go next. Librarians also noticed that students were not using the library's catalog and article databases as much they should be. One interesting 
occurrence was when one of the students, whose topic was subliminal advertising, found a book on her topic and then found a web site that contradicted everything in the book. She wrote about her dilemma over which source to believe and ultimately decided to use the information from the book. Librarians also noticed that, when students did search for books using the library catalog, they tended to search incorrectly. Since this led to no useful results, students were quickly frustrated and turned to search engines.

From these discussions, the library's liaison took these comments to the communication coordinator and it was decided that for spring 2002, at least half of the required sources for the students' informative and persuasive speeches would come from the library's resources, either books or articles. As a result, the information literacy curriculum was changed for the spring semester and librarians spent two full days highlighting different searching techniques for databases and making database comparisons.

The positive effective of the curriculum change were clearly seen in the Paper Trail assignments turned in by the students that semester. When librarians discussed and compared students' papers, they noticed a better understanding of database searching and more effective use of web sites depending on the speech topic. For example, students were more likely to use information from government and professional association web sites, rather than general internet sites.Librarians also saw that students were using more books and articles to get information for their speeches and by visiting the class when the speeches were given, librarians and the communication professors could see that the quality of the speeches increased. 
Although there was no precise measure at the beginning of the semester, students were asked to rate how comfortable they were searching for books, articles, and websites. Students were more comfortable searching for website than for books or articles. Based on the results from the mid-term and final exams, and the students' completion of the information literacy assignments, including the Paper Trail, librarians were able to determine that students had further developed their information literacy skills. From the Paper Trail papers, librarians were able to see that students were exploring new information resources, which led to them finding materials that strengthened their speeches.

\section{Conclusion}

Was the Paper Trail effective? Based on the papers examined in the two semsters, the answer is yes. The papers provided an excellent way for librarians to study students' research process. The information gained from student papers provided a way for librarians to see if the learning objectives for the course were being met and areas of the curriculum students were having difficulty learning. These insights led to changes in the curriculum.

When considering the assessment of information literacy skills, both quantitative and qualitative methods are necessary. The idea of using the Paper Trail as a method for information literacy assessment can be applied to a variety of courses, including standalone information literacy courses and library sessions integrated in specific disciplines. 


\section{Bibliography}

Angelo, T. (1996). Reassessing (and defining) assessment. AAHE Bulletin, 48(3), 7-9.

Carter, E. (2002). Doing the Best you can with what you have: Lessons learned from outcomes assessment. Journal of Academic Librarianship, 28(1), 36-41.

D’Angelo, B. J. (2001). Integrating and assessing information competencies in a gateway course. Reference Services Review, 29(4), 282-293.

Faust, J., Ginno, E., Laherty, J., \& Manuel, K. (2001). Teaching Information Literacy to Generation Y: Tested strategies for reaching the headphone-wearing, itchy mouse-

fingered, and frequently paged. A poster session for the ACRL $10^{\text {th }}$ National

Conference. Retrieved August 19, 2003, from

http://www.library.csuhayward.edu/staff/ACRL/.

Knight, L.A. (2002). The role of assessment in library user education. Reference Services Review, 30(1), 15-24.

List, C. (1998). An Introduction to Information Research. Dubuque, IA: Kendall/Hunt Publishing Company. 
MacDonald, M., Burkhardt, J. \& Kinnie, J. (n.d.). University of Rhode Island Application for Course Approval for General Education Program for LIB 120. Retrieved August 19, 2003, from http://www.uri.edu/facsen/LIB120.html.

Maughan, P.D. (2001). Assessing information literacy among undergraduates: A discuss of the literature and the University of California-Berkeley assessment experience. College \& Research Libraries, 62(1), 71-85.

Rabine, J., \& Cardwell, C. (2000). Start making sense: Practical approaches to outcomes assessment for libraries. Research Strategies, 17(4), 319-335.

Report of the Provost's Advisory Task Force on General Education. (1999). Implementation Guidelines: State University of New York Baccalaureate Candidate General Education Requirement. Retrieved August 19, 2003, http://www.sysadm.suny.edu/Provost/website/adviscouncil.pdf.

Schwandt, T. A. (1997). Qualitative Inquiry: A dictionary of terms. Thousand Oaks: CA: SAGE Publications, Inc.

Williams, J. L. (2000). Creativity in assessment of library instruction. Reference Services Review, 28(4), 323-334. 
Appendix A.

\section{PAPER TRAIL}

\section{A.1 OVERVIEW}

In conjunction with the completion of your information speech, each student will argue for the merit of the research process that led them to create their speeches in this two-tofour page essay. The Paper Trail should allow the librarian and the communication professor to trace all of a student's research. This assignment is due the day of your speech and is worth 50 points.

\section{A.2 PROCEDURES}

1. As you start your research for your information speech, start keeping a log of your research process. Your log can then be converted into a narrative essay.

2. Key information to include:

- What is your topic?

- When did you start your research?

- What type of information do you need?

- Where did you look?

- What search terms did you use?

- Did you try different terms?

- What worked when searching for information?

- What was unsuccessful? 
- Any thoughts on why certain things didn't work?

3. Reflection on your research process

- Was there anything you wish you had done differently?

- Did you feel comfortable searching for a variety of information?

- Did you feel you had the skills necessary to be a successful searcher?

- What did you learn from this experience of documenting your research process?

\section{A.3 GRADING CRITERIA}

1. Writing

- Is the paper well organized?

- Does it include a description of the topic?

- Is it free from errors?

2. Narrative Essay Based on Research Log

- Did you identify the need for information?

- Is this on a topic you already know a lot about or is background research necessary?

- Did you determine what types of information were needed? Did you consider books, articles, websites? Did you justify why you used particular types of information over others?

- Did you utilize a variety of locations where resources can be found? (within and outside the library) 
- Did you conduct Boolean searches to find relevant information?

- Did you clearly explain your thought process while conducting your research? Including analyzing information you found for relevance and credibility.

3. Reflection

- Did you reflect on your process including anything that might be done differently?

- Did you reflect on what was learned from this experience?

4. Citation Style

- Did you include 5 citations for sources used?

- Did you cite your sources in proper APA/MLA format? 